\title{
O Enfoque Ontossemiótico: uma análise da geometria na coleção de livro didático de Matemática no Ensino Técnico Integrado ao Médio
}

\author{
Wagner Barbosa de Lima Palanch \\ Renata Barbosa Ferreira
}

\begin{abstract}
Resumo: 0 presente artigo tem como objetivo apresentar alguns resultados da dissertação de mestrado intitulada "Análise da geometria na coleção de livro didático de Matemática no Ensino Técnico Integrado ao Médio do Centro Paula Souza", desenvolvida no Programa de Mestrado Profissional de Ensino de Ciências e Matemática da Universidade Cruzeiro do Sul em São Paulo, tendo como pressupostos uma perspectiva investigativa que visa analisar qualitativamente materiais curriculares (livro didático) de uma coleção do Ensino Médio no âmbito da geometria. Para análise em questão, foram utilizados quadros desenvolvidos a partir das adequações didáticas (epistêmica, mediacional e ecológica) oriundas dos pressupostos do Enfoque Ontossemiótico. Assim, este artigo discorrerá sobre os quadros de adequação didática supramencionado visando oferecer subsídios para que professores possam guiar-se ao analisarem livros didáticos.
\end{abstract}

Palavras-chave: Enfoque Ontossemiótico. Geometria. Livro Didático. Materiais Curriculares.

Wagner Barbosa de Lima Palanch Doutor e Mestre em Educacão Matemática pela Pontifícia Universidade Católica de São Paulo. Professor do Programa de Pós Graduação em Ensino de Ciências e Matemática da Universidade Cruzeiro do Sul (UNICSUL).

(iD) https://orcid.org/0000-0001-9473-

$\triangle$ wagnerpalanch@gmail.com

Renata Barbosa Ferreira Mestre em Ensino de Ciências e Matemática da Universidade Cruzeiro do Sul (UNICSUL). Professora de Matemática no Ensino Técnico Integrado ao Médio do Centro Paula Souza.

iD https://orcid.org/0000-0002-8318-

$\triangle$ re.mic@hotmail.com

Recebido em 02/06/2021

Aceito em 04/07/2021

Publicado em 07/07/2021

\section{The Ontosemiotic Approach: an Analysis of Geometry in the Mathematics Textbook Collection in Technical Education Integrated to High School}

Abstract: This article aims to present some results of the master's dissertation entitled "Analysis of geometry in the collection of textbook of Mathematics in Technical Education Integrated to Middle School at the Paula Souza Center", developed in the Professional Master's Program in Science and Mathematics Teaching at Cruzeiro do Sul University in São Paulo, assuming an investigative perspective that aims to qualitatively analyze curricular materials (textbook) from a collection of High School in the scope of geometry. For the analysis in question, tables developed from the didactic adjustments (epistemic, mediational and ecological) originated from the assumptions of the Ontossemiotic Approach were used. Thus, this article will discuss the aforementioned didactic adequacy frameworks in order to offer subsidies so that teachers can guide themselves when analyzing textbooks.

Keywords: Ontosemiotic approach. Geometry. Textbook. Curricular Materials.

\section{El Enfoque Ontosemiótico: un análisis de la geometría en la colección de libros de texto de matemáticas en la educación técnica integrada a la escuela secundaria}

Resumen: Este artículo tiene como objetivo presentar algunos resultados de la tesis de maestría titulada "Análisis de la geometría en la colección de libro de texto de Matemática en Educación Técnica Integrada a Secundaria en el Centro Paula Souza", desarrollada en el Programa de Maestría Profesional en Docencia de Ciencias y Matemáticas en Cruzeiro do Sul en São Paulo, asumiendo una perspectiva investigativa que tiene como objetivo analizar cualitativamente los materiales curriculares (libro de texto) de una colección 
de Bachillerato en el ámbito de la geometría. Para el análisis en cuestión se utilizaron tablas desarrolladas a partir de los ajustes didácticos (epistémicos, mediacionales y ecológicos) originados a partir de los supuestos del Enfoque Ontossemiótico. Así, en este artículo se discutirán los marcos de adecuación didáctica antes mencionados con el fin de ofrecer subsidios para que los docentes puedan orientarse a la hora de analizar los libros de texto.

Palabras clave: Abordaje ontosemiótico. Geometría. Libro de texto. Materiales curriculares.

\section{Introdução}

Os materiais curriculares, de modo geral, caracterizam-se como ferramentas para serem utilizadas na prática pedagógica, isto é, um instrumento que auxilia no processo de ensino e aprendizagem.

O termo "material curricular" é definido de maneiras diferentes por diversos autores. No sentido amplo, esse termo refere-se a todos os instrumentos ou ferramentas que fornecem ao professor diretrizes e critérios para a orientação e intervenção no processo de ensino e aprendizagem. Assim, materiais curriculares são ferramentas que auxiliam o professor em sua prática pedagógica.

Buscando clarificar a diversidade de materiais que compõem a noção de materiais curriculares, Pires (2016) e Palanch (2016) destacam que os tipos de materiais como: (i) materiais de escritas, como livros didáticos, ficha de trabalho ou livro mais especializado (utilizados para suporte, são materiais referentes aos conteúdos); (ii) materiais manipuláveis, como o geoplano ou instrumentos de medidas (materiais relacionados com conteúdo atitudinal); (iii) materiais tecnológicos, como computador ou calculadora (materiais relacionados à esfera estritamente processual); (iv) outros materiais, como quadro preto ou retroprojetor (materiais de intervenção do professor).

O livro didático configura-se como uma fonte de conhecimento impressa e frequentemente utilizada por grande parte dos professores e alunos. Nesse sentido, assume um papel importante no processo de ensino-aprendizagem, pois influencia o trabalho pedagógico e a rotina da sala de aula.

Em estudos sobre livros didáticos, Batista (1999) discorre sobre os textos impressos e livros didáticos como um objeto variável e instável. 0 autor julga que o livro didático e a escola determinam relações com o mundo da cultura; portanto as produções culturais e a dimensão social devem ser compreendidas de modo indissociáveis. $\mathrm{O}$ autor apresenta a história do livro didático a partir de outras fontes documentais, como os manuscritos, ressaltando a quantidade de informações sobre o livro didático. Em seu estudo, a área da história sociocultural é bem evidente 
revelando elementos cognitivos e afetivos da leitura de modo a colaborar na reconstrução das vivências de leitores num espaço escolar.

Portanto, o livro didático é um instrumento específico e importantíssimo no processo de ensino e de aprendizagem formal. Dessa forma, ele deve estar incluso nas políticas educacionais para o poder público cumprir sua parte na garantia de educação de qualidade para todos. Por essa mesma razão, a escolha e o seu uso necessitam ser fundamentadas na competência dos professores que, em conjunto com os alunos, o transformará em instrumento de aprendizagem (LAJOLO, 1996).

Com a criação do Programa Nacional do Livro Didático (PNLD) em 1985, nos aspectos relacionados à escolha e ao uso de livros didáticos nas escolas públicas brasileiras tiveram novos encaminhamentos políticos e pedagógicos (CAVALCANTI, 2016). Nesse sentido, os professores possuem maior autonomia na escolha do livro didático e os alunos passaram a ter aquisição dos livros, de melhor qualidade na maior parte das disciplinas do currículo escolar (RIBEIRO e PALANCH, 2019).

Considerando que o PNLD concretizado por meios de procedimentos que buscam garantir o direito de alunos e professores de escolas públicas a terem acesso a livros didáticos de melhor qualidade, é necessário ressaltar que esses investimentos estejam em função da prática docente, de maneira que, ao apresentarem os conteúdos, apontem propostas de atividades diversificadas que potencializem o desenvolvimento dos processos de ensino e aprendizagem.

Considerando a magnitude deste programa, acreditamos que pesquisas que abranjam a análise de livros didáticos precisam ainda ser ampliadas, visto a importância destes recursos para a Educação Brasileira. Da mesma forma, enxergamos o estudo da geometria como altamente relevante para a ciência, uma vez que desenvolve o raciocínio por meio das formas e permite ampliar a visão e orientação espacial, além de sua vasta aplicação na vida cotidiana, auxiliando inclusive na compreensão e resolução de questões de outras áreas do conhecimento humano.

Assim, buscando discutir essas reflexões, emergiu este estudo, o qual buscou investigar o desenvolvimento da Geometria no ensino técnico integrado ao médio das escolas técnicas da instituição Centro Paula Souza do Estado de São Paulo, sob a perspectiva do Enfoque Ontossemiótico do Conhecimento e a Instrução Matemática (EOS), como possibilidade teórica e didática para analisar o tema de Geometria no livro didático de Matemática. 


\section{Enfoque Ontossemiótico}

O Enfoque Ontossemiótico proposto para fundamentar este estudo foi desenvolvido por Godino e seus colaboradores, os quais desenvolveram, através de diversos trabalhos, um grupo de noções teóricas que constituem um enfoque ontológico-semiótico, cuja principal característica é a articulação dos aspectos epistemológicos e semióticos do conhecimento e da Didática Matemática.

O Enfoque Ontossemiótico do Conhecimento e da Instrução Matemática é um modelo teórico que busca integrar outros modelos teóricos empregados na pesquisa em Educação Matemática baseado nos princípios antropológicos e semióticos sobre a matemática e instituído de princípios didáticos socioconstrutivistas e interacionistas para o estudo do processo de ensino e aprendizagem (GODINO; BATANERO e FONT, 2008).

O modelo EOS é estruturado a partir de critérios os quais permitem a avaliação e melhoria dos processos de ensino e aprendizagem de matemática, apropriando-se de concepções pragmáticas e realistas sobre o significado dos objetos matemáticos dependendo do contexto na qual estão inseridos, e concepções antropológicas e semióticas do conhecimento matemático, tanto do aspecto institucional como do pessoal (GODINO, 2012).

O Enfoque Ontossemiótico descreve os cinco níveis de análises que subsidiam planejamento, implementação e avaliação no processo educativo: (I) Sistemas de Práticas, (II) Configurações de Objetos e Processos Matemáticos, (III) Configurações Didáticas, (IV) Dimensão Normativa e (V) Idoneidade (adequação) Didática (RIBEIRO e PALANCH, 2019).

De acordo com Godino, Batanero e Font (2008), esse enfoque refere-se, especificamente, ao conhecimento matemático e à instrução essencial para seu desenvolvimento. As dimensões pessoal e institucional do conhecimento matemático são levadas em conta na intenção de comparar e articular diferentes enfoques que investigam o ensino e a aprendizagem, caminhando rumo a um modelo da cognição e instrução matemática.

Para os autores, a EOS inicia-se na formulação de uma ontologia de objetos matemáticos tendo em vista o triplo aspecto da atividade matemática como atividade socialmente partilhada de resolução de problemas, como linguagem simbólica e como sistema conceitual logicamente organizado (GODINO; BATANERO e FONT, 2008, p. 11).

Buscando chegar a um acordo com as reflexões, a aplicação do modelo teórico do Enfoque Ontossemiótico do Conhecimento e da Instrução Matemática (EOS), se tornou necessária para esta pesquisa, dado que sua aplicabilidade na análise de materiais curriculares leva em conta o conceito de adequação didática, oportunizando avaliar os processos de instrução a partir de quadros de análise.

Como a presente pesquisa é um estudo de análise de livros didáticos optou-se pela Adequação Didática, pois ela abrange seis componentes que permitem a identificação de pontos que carecem de 
aperfeiçoamento para futuras intervenções no processo de ensino e aprendizagem da Matemática, das quais três (epistêmica, ecológica e mediacional) são empregadas para analisar manuais escolares.

\subsection{Adequação Didática}

Segundo Godino (2011) a noção de adequação didática caracteriza-se em uma ferramenta de análise que permite a passagem de uma didática descritiva e explícita para uma didática normativa, ou seja, que possibilita a orientação da prática do professor em sala de aula de modo a proporcionar melhorias na qualidade do ensino da Matemática.

Para Godino (2021) é necessário levar em consideração a especificidade do conteúdo matemático sobre o qual é realizada a concepção do seu ensino e aprendizagem, a decomposição analítica dos problemas de investigação nas dimensões epistêmica, cognitiva, mediacional, interacional, emocional e ecológica que atenda ao objetivo descritivo e explícito do problema abordado e os critérios que auxiliam, na prática docente, ao estudo de conteúdos matemáticos específicos aos conhecimentos descritivos e explícitos.

Dessa forma, a adequação didática abrange a articulação sistemática e coerente das dimensões: epistêmica, cognitiva, mediacional, interacional, emocional e ecológica, que interagem entre si podem ser notadas a partir de diferentes graus de adequação (alta, média e baixa).

De acordo com Godino, Batanero e Font (2008), as seis dimensões de uma adequação didática, correspondem:

- Adequação epistêmica: refere-se ao grau de representatividade dos significados institucionais implementados (ou pretendidos), com relação ao significado de referência, ou seja, diz respeito ao estudo dos temas da Matemática organizados pela instituição de ensino, bem como a distribuição dos descritores de situações-problemas, linguagem, procedimentos, definições, propriedade e argumentos.

- Adequação cognitiva: demonstra 0 grau em que os significados pretendidos/implementados estão na zona de desenvolvimento potencial dos alunos, tal quanto a proximidade destes significados pessoais atingidos aos significados pretendidos/implementados.

- Adequação interacional: diz respeito à interação entre professor e aluno, detectando e resolvendo conflitos de significados e favorecendo a construção da autonomia na aprendizagem. 0 processo de ensino e aprendizagem terá maior adequação do ponto de vista da interação se as configurações e itinerários didáticos proporcionarem constatar potenciais conflitos semióticos (percebidos a priori), por um lado, e, por outro resolver os conflitos que podem surgir durante o processo de instrução.

- Adequação mediacional: grau de disponibilidade e adequação dos recursos materiais e temporais necessários para o desenvolvimento do processo de ensino e aprendizagem, ou seja, o uso de 
recursos manipuláveis, tempo para realizar as tarefas e as condições do ambiente da sala de aula são fatores fundamentais para o desenvolvimento do processo de ensino e aprendizagem.

- Adequação emocional: grau de interesse ou motivação do aluno com relação aos conhecimentos matemáticos e o processo de estudo. A adequação emocional está associada com fatores que dependem tanto da instituição como do aluno e de sua história escolar.

- Adequação ecológica: refere-se ao grau em que o processo de estudo se ajusta ao projeto educativo da escola, à sociedade e aos condicionamentos do contexto no qual se desenvolve.

A figura 1 a seguir, mostra o hexágono regular representa um processo de estudo planejado, que corresponde a um grau de nível alto de adequações parciais. Já, o hexágono irregular interno representa às adequações efetivamente alcançadas após o desenvolvimento de um processo de estudo.

Figura 1 - Componentes da Adequação Didática

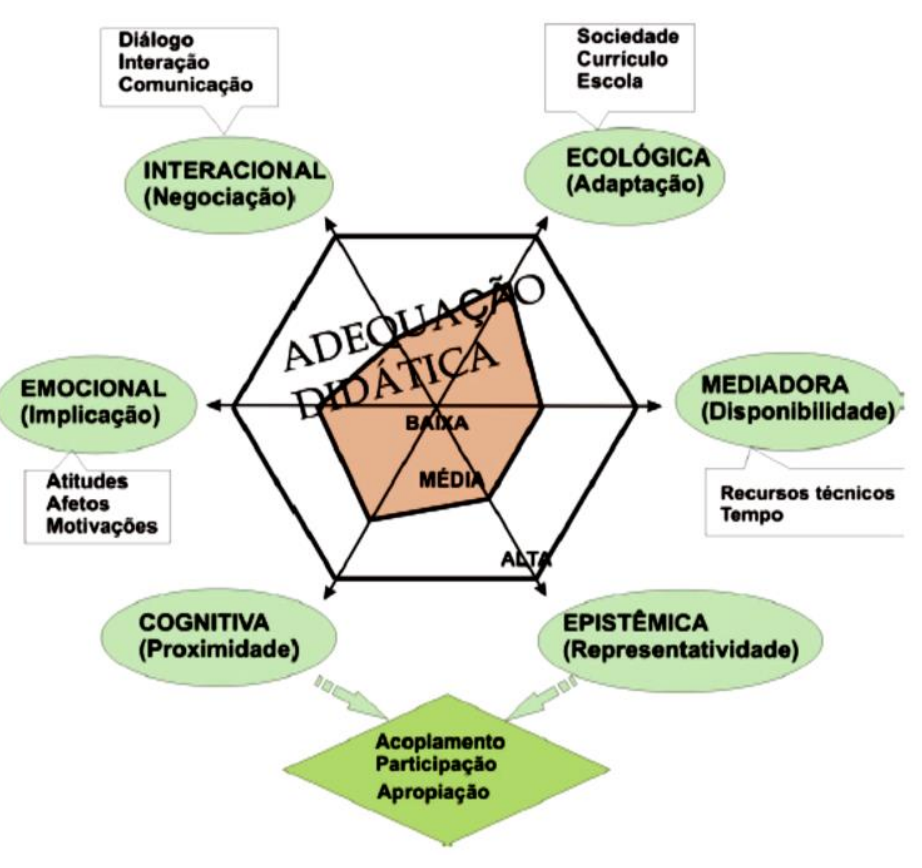

Fonte: Godino, Batanero e Font (2008, p. 24)

\section{Materiais e Métodos}

Para análise das adequações epistêmica, mediacional e ecológica da coleção de livros didáticos selecionados para esta pesquisa optamos em adaptar a grade de análise de Fonseca (2013), bem como os indicadores propostos por Godino (2011). Especificamente, foi inserido um tipo dos conhecimentos 
emergente, o problemas-processo ou heurísticos ${ }^{1}$ do autor Dante (2015). A seguir, apresentam-se os descritores e as categorias da adequação didática.

Quadro 1 - Adequação Epistêmica

\begin{tabular}{|c|c|c|c|}
\hline \multicolumn{4}{|c|}{ ADEQUAÇÃO EPISTÊMICA } \\
\hline Categorias & \multicolumn{2}{|c|}{ Subcategorias } & Análise do livro \\
\hline \multirow{8}{*}{ 1. Situações } & \multicolumn{2}{|c|}{1.1 Introdução / Motivação } & $\begin{array}{l}\text { - As atividades introdutórias, na } \\
\text { Geometria, utilizam-se de situações da } \\
\text { própria Matemática, outras áreas de } \\
\text { conhecimento ou da vida real? } \\
\text { - São apresentadas por imagens, texto } \\
\text { informativo ou científico? } \\
\text { - Apresenta proposta de resolução ou } \\
\text { não? }\end{array}$ \\
\hline & 1.2 Exemplos (tarefa & esolvidas) & $\begin{array}{l}\text { - Os exemplos se localizam antes ou } \\
\text { depois da definição formal? } \\
\text { - São apresentados com qual intenção? } \\
\text { - A resolução é completa ou incompleta? } \\
\text { De modo formal ou intuitivo? } \\
\text { - Exercícios contextualizados ou formais? }\end{array}$ \\
\hline & \multirow{6}{*}{$\begin{array}{l}1.3 \text { Tarefas (que os } \\
\text { autores propõem ao } \\
\text { aluno) }\end{array}$} & $\begin{array}{l}\text { Conhecimentos } \\
\text { Prévios }\end{array}$ & $\begin{array}{l}\text { - Utilizam-se de atividades que testam os } \\
\text { conhecimentos prévios antes da definição } \\
\text { formal? } \\
\text { - Utilizam-se de atividades de retomada } \\
\text { de conceitos? }\end{array}$ \\
\hline & & \multirow{5}{*}{$\begin{array}{l}\text { Conhecimentos } \\
\text { Emergentes }\end{array}$} & $\begin{array}{l}1 \text { - Representação visual : Sugere } \\
\text { construções geométricas ou localização } \\
\text { de pontos no plano cartesiano, em malha } \\
\text { quadriculada, em softwares }\end{array}$ \\
\hline & & & $\begin{array}{l}2 \text { - Cálculo: Perímetro, áreas, volumes, } \\
\text { ângulos, medidas de lados, distâncias, } \\
\text { etc. }\end{array}$ \\
\hline & & & $\begin{array}{l}3 \text { - Exploração: atividades que permitam } \\
\text { selecionar ferramentas mais apropriadas } \\
\text { para a resolução de um problema }\end{array}$ \\
\hline & & & $\begin{array}{l}4 \text { - Aplicação da definição: faz o uso da } \\
\text { definição para resolver problemas, utiliza- } \\
\text { se de sistema dedutivo (conceitos } \\
\text { primitivos, postulados e teoremas) }\end{array}$ \\
\hline & & & $\begin{array}{l}5 \text { - Aplicação de uma propriedade: } \\
\text { interpreta e utiliza certa propriedade em } \\
\text { uma atividade. }\end{array}$ \\
\hline
\end{tabular}

1 Dante (2005) classifica tipos de Problemas-processo ou heurístico como problemas cuja solução envolve as operações que não estão contidas no enunciado, requer do aluno tempo para pensar e planejar uma ação, uma estratégia que poderá levá-lo a uma solução. Problemas com estas características despertam o interesse e a curiosidade do aluno e favorecem o desenvolvimento da criatividade 


\begin{tabular}{|c|c|c|}
\hline & & $\begin{array}{l}6 \text { - Conjecturas e argumentação: } \\
\text { atividades que permitem apresentar um } \\
\text { resultado com embasamento sólido. }\end{array}$ \\
\hline & & $\begin{array}{l}7 \text { - Prova: argumento que valida uma } \\
\text { preposição ou procedimento que } \\
\text { apresentam componentes indutivos, } \\
\text { empíricos ou lógico-dedutivos. }\end{array}$ \\
\hline & & $\begin{array}{l}8 \text { - Modelação Matemática: } \\
\text { Atividades contextualizadas e } \\
\text { vivenciadas pelo leitor, que busca } \\
\text { descobrir formas de resolver } \\
\text { determinadas situações. }\end{array}$ \\
\hline & & $\begin{array}{l}9 \text { - Problemas-processo ou heurísticos: } \\
\text { tarefas que não depende de aplicação } \\
\text { automática de algum algoritmo cuja } \\
\text { solução envolve operações que não estão } \\
\text { contidas no enunciado. }\end{array}$ \\
\hline 2. Linguagem & & $\begin{array}{l}\text { - Verbal, numérica, algébrica, figural ou } \\
\text { tabelar. }\end{array}$ \\
\hline 3. Conceitos & & $\begin{array}{l}\text { - Os conceitos geométricos são } \\
\text { desenvolvidos de uma única definição? } \\
\text { - Formal ou intuitiva? }\end{array}$ \\
\hline & 4.1. Tipo de exposição & - São apresentadas formal ou intuitiva? \\
\hline 4. Proposições & 4.2. Prova-se ou não & $\begin{array}{l}\text { - Provam, justificam ou somente se } \\
\text { expõem? }\end{array}$ \\
\hline & 4.3. Empregam-se ou expõem-se & $\begin{array}{l}\text { - Utilizam-se em tarefas resolvidas, em } \\
\text { atividades de revisão, de aplicação, de } \\
\text { ampliação? }\end{array}$ \\
\hline & 5.1. Faz uso de diversas abordagens & $\begin{array}{l}\text { - Apresentam-se variedades de } \\
\text { procedimentos para resolver as atividades } \\
\text { ou somente um para cada caso? }\end{array}$ \\
\hline $\begin{array}{l}5 . \\
\text { Procedimentos }\end{array}$ & 5.2. Justificam-se ou não & $\begin{array}{l}\text { - Os procedimentos são justificados ou } \\
\text { apenas expostos como método habitual? }\end{array}$ \\
\hline & 5.3. Faz uso de novas tecnologias & $\begin{array}{l}\text { - Utilizam-se de recursos tecnológicos } \\
\text { (softwares de geometria dinâmica, } \\
\text { calculadoras e etc)? }\end{array}$ \\
\hline $\begin{array}{l}6 . \\
\text { Arqumentacão }\end{array}$ & $\begin{array}{l}\text { 6.1. Emprega uma prática discursiva para } \\
\text { convencer da validade de determinadas } \\
\text { propriedades, baseada na linguagem natural, } \\
\text { gráfica e outros }\end{array}$ & $\begin{array}{l}\text { - Apresenta uma linguagem discursiva } \\
\text { que justifique os procedimentos? } \\
\text { - Qual tipo de linguagem? }\end{array}$ \\
\hline & 6.2. Tipo de prova usada & $\begin{array}{l}\text { - Empírica, indutiva, lógica-dedutiva, } \\
\text { contraexemplos, equivalência, etc.) }\end{array}$ \\
\hline
\end{tabular}

Fonte:Adaptado de Fonseca (2013), Godino (2011) e Dante (2015) 
Quadro 2 - Adequação Mediacional

\begin{tabular}{|l|l|}
\hline \multicolumn{2}{|c|}{ ADEQUAÇÃO MEDIACIONAL } \\
\hline \multicolumn{1}{|c|}{ Categorias } & \multicolumn{1}{|c|}{ Subcategorias }
\end{tabular}

Fonte:Adaptado de Fonseca (2013) e Godino (2011)

Quadro 3 - Adequação Ecológica

\begin{tabular}{|l|l|l|}
\hline \multicolumn{2}{|c|}{ ADEQUAÇÃO ECOLÓGICA } \\
\hline \multicolumn{1}{|c|}{ Categorias } & \multicolumn{1}{c|}{ Análise do Livro } \\
\hline 9. Adaptação do currículo & $\begin{array}{l}\text { - O conteúdo está alinhado com as diretrizes curriculares } \\
\text { - Apresenta revisão de pré-requisitos em com conformidade com } \\
\text { o currículo }\end{array}$ \\
\hline 10. Abertura para a inovação didática & $\begin{array}{l}\text { - Inova com base na investigação e na prática reflexiva } \\
\text { - Faz integração de novas tecnologias }\end{array}$ \\
\hline 11. Adaptação socioprofissional e cultural & $\begin{array}{l}\text { - O conteúdo contribui para a formação socioprofissional dos } \\
\text { alunos }\end{array}$ \\
\hline 12. Educação em valores & $\begin{array}{l}\text { - Abrange a educação de valores democráticos e do pensamento } \\
\text { crítico }\end{array}$ \\
\hline 13. Conexões intra e interdisciplinares & $\begin{array}{l}\text { - Os conteúdos relacionam-se com outros conteúdos intra e } \\
\text { interdisciplinares }\end{array}$ \\
\hline
\end{tabular}

Fonte: Adaptado de Fonseca (2013)

Os fundamentos apresentados nos quadros, revela a aplicabilidade dos componentes da adequação didática do Enfoque Ontossemiótico para analisar o livro didático, pois eles constituem várias categorias que permitem compreender e observar as perspectivas e intencionalidade de um material curricular. Desse modo, os quadros configuram-se como um dispositivo que o professor pode utilizar como orientador para comprovar quais componentes didáticos são predominantes, pouco explorados ou ainda ausentes. Assim, possibilitando selecionar e adaptar tarefas que colaborem qualitativamente no desenvolvimento do ensino e da aprendizagem.

\section{Análise e Discussão do Livro Didático}

Nesta seção será apresentada a análise do volume 1 que compõem a coleção do livro didático Matemática: contexto \& aplicação (2016), do autor Luiz Roberto Dante, com o objetivo de analisar quais são os componentes da adequação epistêmica, ecológica e mediacional que se destacam com frequência no livro didático referente ao tema de Geometria no Ensino Médio? 


\section{revemop}

A seguir Apresentaremos os quadros de análise com as descrições completas sobre as situações didáticas do volume 1 do livro didático tendo em vista os indicadores e resultados, sendo realizada a discussão dos dados à luz das adequações didáticas.

Neste volume, o autor introduz semelhança de triângulos com um texto da história sobre Tales de Mileto.

Figura 2 - Texto da história da Matemática

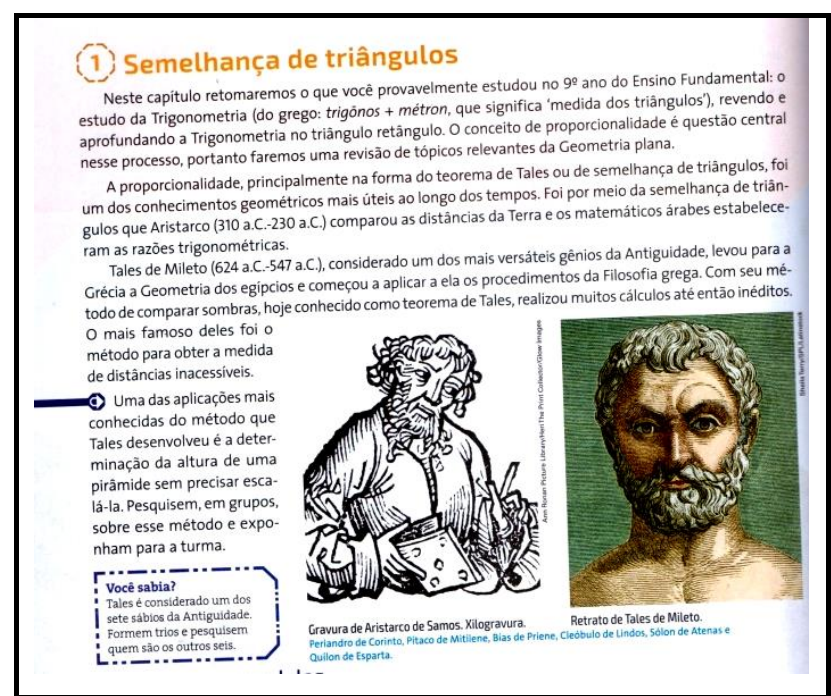

Fonte: Dante (2016, p. 236)

Em seguida, o autor faz a demonstração de forma mais usual do Teorema de Tales com uso de diagrama de feixes de retas paralelas intersectados por duas retas transversais, passo a passo evidenciando a propriedade da proporções. Na sequência, são apresentados exercícios resolvidos e atividades de aplicação da definição, sugeridos em dupla ou em equipe pelos alunos. 
Figura 3 - Exercícios resolvidos - Teorema de Tales

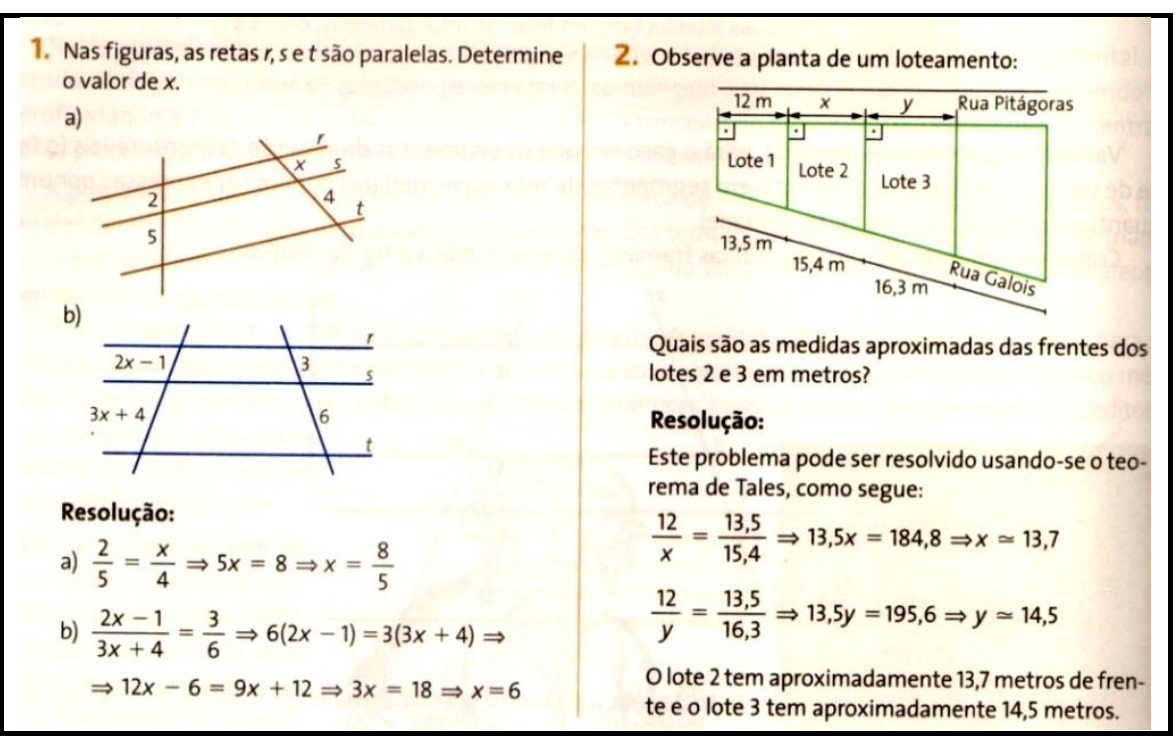

Fonte: Dante (2016, p. 238)

Na sequência da apresentação de exercícios resolvidos que envolve semelhanças, são propostas atividades que requerem a argumentação (exemplo: Figura 4) e outros que exigirão 0 reconhecimento da propriedade que torna os triângulos semelhantes (exemplo: Figura 5) observando que os triângulos apesar de semelhantes, não estão na mesma posição: portanto os lados homólogos não estão sobre a mesma reta.

Figura 4 - Tarefa de argumentação semelhanças de triângulos - I

7. Justifique a semelhança dos triângulos $A B C$ e $D E C$.

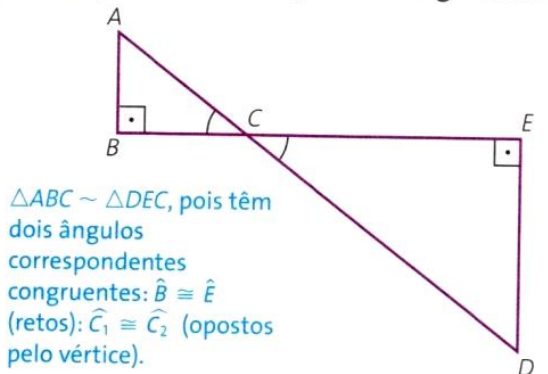

Fonte: Dante (2016, p. 243) 
Figura 5 - Tarefa de argumenta- semelhanças de triângulos

12. Dos três triângulos desta figura $(\triangle A B C, \triangle B C D$ e $\triangle A B D)$, há dois que são semelhantes. Quais são eles?

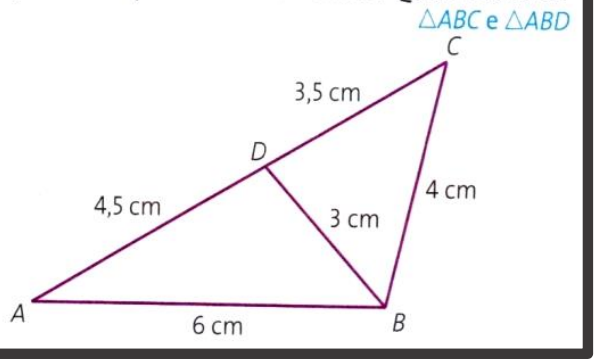

Fonte: Dante (2016, p. 243)

Os demais exercícios são expostos de forma que se reconheça o que torna os triângulos semelhantes com base nos conceitos já adquiridos. 0 autor apresenta uma atividade de aplicação de propriedade do teorema fundamental da semelhança.

Figura 6 - Tarefa de aplicação de uma propriedade

13. Determine o valor de $x$ na figura abaixo: $x=4$

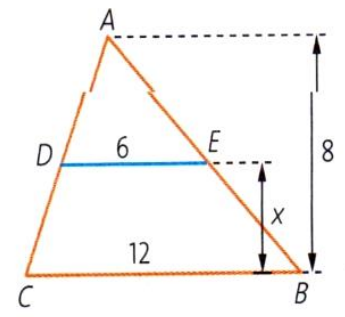

Fonte: Dante (2016, p. 243)

Dando continuidade, é apresentado o uso de semelhança para medir distâncias inacessíveis por meio de uma situação contextualizada e atividade com material manipulável. 
Figura 7 - Uso de semelhança para distância inacessíveis

\section{Uso de semelhança para medir distâncias inacessíveis}

Como medir a altura de um prédio, de uma árvore, de um poste?

Neste capítulo aprenderemos que há muitas maneiras. Por exemplo, poderiamos medir essas alturas indiretamente usando semelhança de triângulos e proporção.

Mais adiante, veremos que também seria possivel usar a Trigonometria. Como fazer isso? Examine este exemplo:

Um jogador de basquete deseja saber a altura em que se encontra uma cesta de basquete oficial em relação ao piso de uma quadra. Como calcular essa altura com o auxilio de um triângulo de papel DFG?

Para isso, ele poderia usar a metade de uma folha de papel quadrada, como indicado nos procedimentos abaixo. Observe que $D G=F G$.

$\left.1^{\circ}\right)$ Mirar o topo da cesta conservando a parte inferior da folha $(\overline{D G})$ paralela ao chão. Talvez ele precise afastar-se ou aproximar-se da cesta para que isso ocorra.

$2^{\circ}$ ) Medir a distância entre ele e a perpendicular ao chão que passa pela cesta: $A B=130 \mathrm{~cm}$ na figura abaixo.

Observe que $A B=D C$. Logo, $D C=130 \mathrm{~cm}$.

$\left.3^{\circ}\right)$ Medir a distância do chão aos seus olhos, na figura:

$$
A D=175 \mathrm{~cm}
$$

Veja que $A D=B C$. Logo, $B C=175 \mathrm{~cm}$.

$\triangle D C E \sim \triangle D G F$ (dois ângulos correspondentes congruentes) Da semelhança dos triângulos $D C E$ e $D G F$, concluímos que:

$$
\frac{D E}{D F}=\frac{D C}{D G}=\frac{E C}{F G}
$$

Observando a última igualdade $\frac{D C}{D C}=\frac{E C}{F G}$ e sabendo que $D G=F G$, concluimos que $D C=E C$.

Assim, a altura da cesta de basquete é dada por: $B C+C E$ na figura:

$$
175 \mathrm{~cm}+130 \mathrm{~cm}=305 \mathrm{~cm}=3,05 \mathrm{~m}
$$
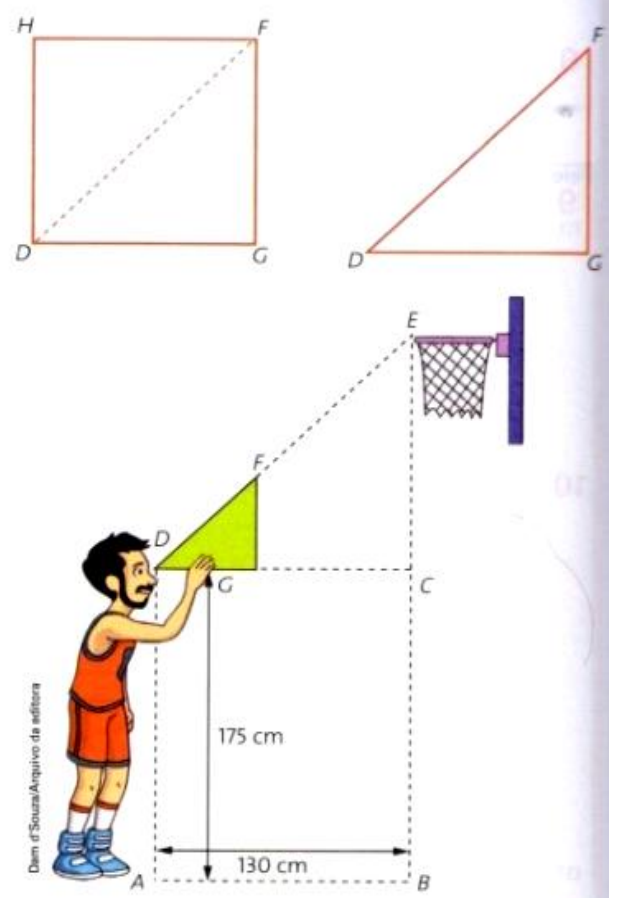

18. Conforme o método usado com a metade de uma folha de papel quadrada, determine a altura do mastro da bandeira do desenho a seguir.

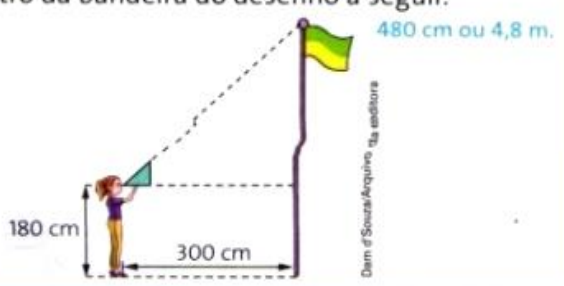

19. 2 Usem o método do exercício anterior e determinem as medidas de algumas alturas (casa, edificio, poste, árvore, etc.). Em seguida, copiem o quadro a seguir no caderno e completem-no. Respostas pessoais.

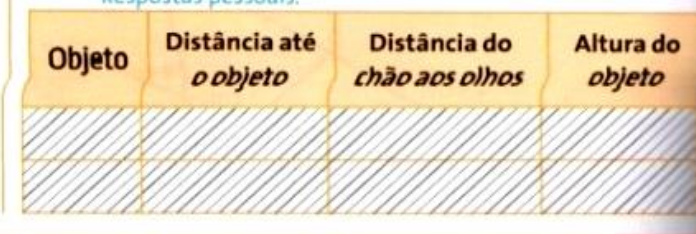

Fonte: Dante (2016, p. 244)

Em seguida, o autor aborda o triângulo retângulo, seus elementos, as relações métricas finalizando com a demonstração do Teorema de Pitágoras com uma abordagem algébrica e geométrica. Segue: 
Figura 8 - Relações métricas no triângulo retângulo

\section{0 triângulo retângulo}

O triângulo retângulo é um dos mais importantes tipos de triângulo, pela utilidade que ele tem em Matemática e na vida cotidiana. Pelo fato de possuir um ângulo reto, o triângulo retângulo é muito usado em Engenharia, em construções de todos os tipos.

Há mais de 5 mil anos, os egípcios já utilizavam triângulos de lados proporcionais a 3, 4 e 5, feitos de corda, para obter ângulos retos.

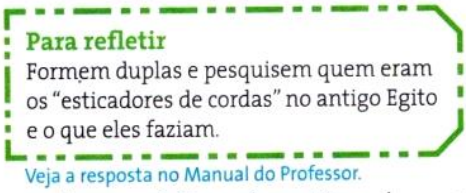

Em um triângulo retângulo, o maior lado é a hipotenusa (lado oposto ao ângulo reto). Os outros dois lados, perpendiculares entre si, são os catetos. Os ângulos agudos são complementares $\left(\alpha+\beta=90^{\circ}\right)$.

\section{Elementos do triângulo retângulo}

Representação de egípcios obtendo triângulo retângulo com nós em cordas.
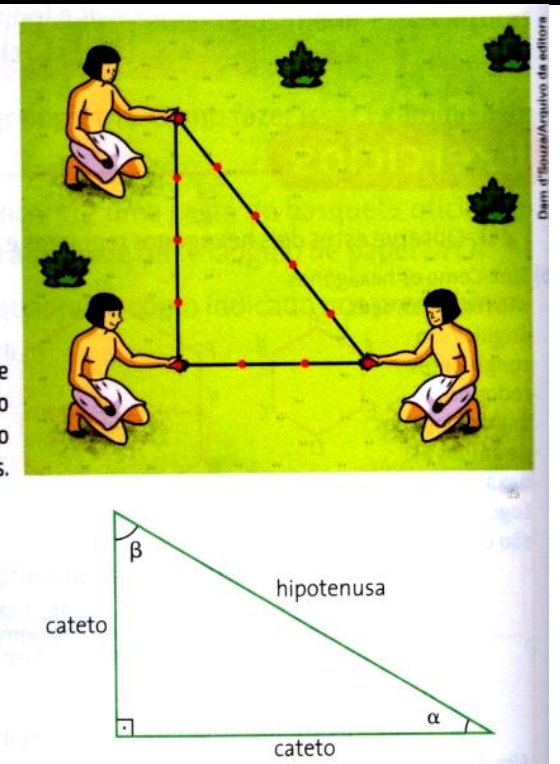

Consideremos um triângulo $A B C$, retângulo em $A$, e o segmento de reta $A D$ perpendicular ao lado $B C$ com $D$ em $\overline{B C}$.

Ficam definidos os seguintes elementos do $\triangle A B C$ :

$\overline{B C} \rightarrow$ hipotenusa (medida $a$ )

$\overline{A C} \rightarrow$ cateto (medida $b$ )

$\overline{A B} \rightarrow$ cateto (medida c)

$\overline{B D} \rightarrow$ projeção do cateto $\overline{A B}$ sobre a hipotenusa (medida $m$ )

$\overline{C D} \rightarrow$ projeção do cateto $\overline{A C}$ sobre a hipotenusa (medida $n$ )

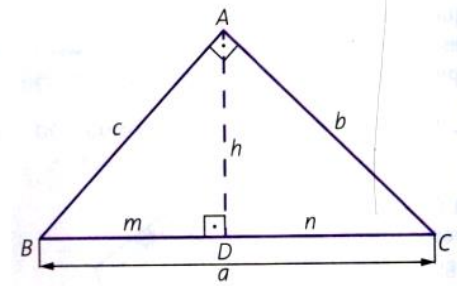

$\overline{A D} \rightarrow$ altura relativa à hipotenusa (medida $h$ )

\section{Relações métricas}

Uma importante aplicação da semelhança de triângulos são as relações métricas no triângulo retângulo: fórmulas que relacionam entre si as medidas dos lados e das alturas do triângulo.

\section{Triângulos semelhantes}

A altura relativa à hipotenusa de um triângulo retângulo $A B C$ divide-o em dois triângulos retângulos semeIhantes a ele e semelhantes entre si. Observe:
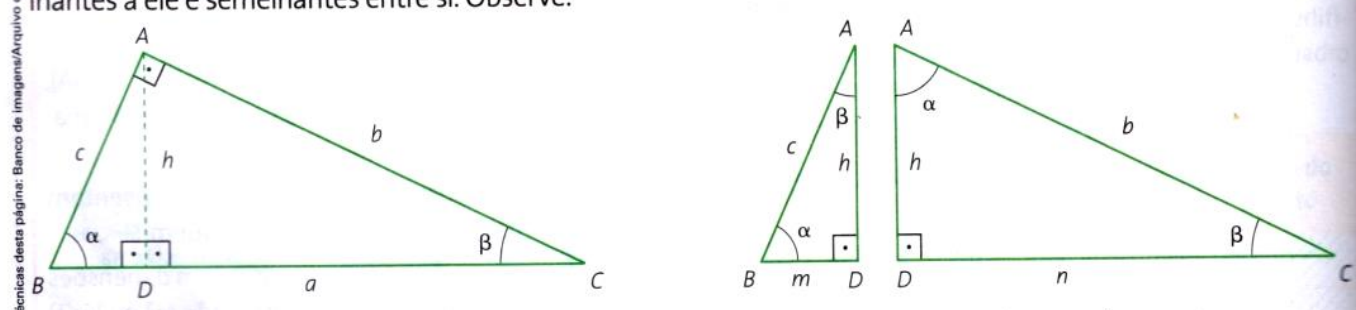

Como os três triângulos têm todos os ângulos congruentes, pelo $1^{\circ}$ caso de semelhança, temos: $\triangle A B C \sim \triangle D B A \sim \triangle D A C$

Fonte: Dante (2016, p. 246) 


\section{As relações métricas}

Da semelhança entre $\triangle A B C$ e $\triangle D B A$, segue que:

$$
\frac{\overline{A B}}{\overline{B C}}=\frac{\overline{D B}}{\overline{B A}} \Rightarrow \frac{c}{a}=\frac{m}{c} \Rightarrow c^{2}=a m
$$

, Fique atento!

Você reparou que as relações (1)

e (III) são as mesmas, apenas

Da semelhança entre $\triangle A B C$ e $\triangle D A C$, temos:

mudam do lado esquerdo para

o lado direito do triângulo $A B C$ ?

$$
\frac{\overline{A B}}{\overline{B C}}=\frac{\overline{D A}}{\overline{A C}} \Rightarrow \frac{c}{a}=\frac{h}{b} \Rightarrow a h=b c
$$

Ambas podem ser

generalizadas como:

cateto ${ }^{2}=$ hipotenusa $\cdot$ projeção

$$
\frac{\overline{A C}}{\overline{B C}}=\frac{\overline{D C}}{\overline{A C}} \Rightarrow \frac{b}{a}=\frac{n}{b} \Rightarrow b^{2}=a n \text { (III) }
$$

Da semelhança entre $\triangle D B A$ e $\triangle D A C$, segue que:

$$
\frac{\overline{D A}}{\overline{D B}}=\frac{\overline{D C}}{\overline{D A}} \Rightarrow \frac{h}{m}=\frac{n}{h} \Rightarrow h^{2}=m n \text { (V) }
$$

Somando membro a membro (1) e (III), temos:

$c^{2}=a m$

$+b^{2}=a n$

$\overline{b^{2}+c^{2}=a m+a n} \Rightarrow b^{2}+c^{2}=a(m+n) \Rightarrow b^{2}+c^{2}=a^{2}$ (V)

\section{A relação (V) é o famoso teorema de Pitágoras: em um triângulo retângulo o quadrado da} medida da hipotenusa é igual à soma dos quadrados das medidas dos catetos.

\section{Outra demonstração do teorema de Pitágoras}

O teorema de Pitágoras também pode ser demonstrado por comparação de áreas (segundo os historiadores, a demonstração de Pitágoras deve ter sido uma demonstração geométrica semelhante à que segue).

As duas regiões quadradas a seguir têm lados de medidas $(b+c)$. Logo, têm a mesma área. Retirando das duas as quatro regiões triangulares congruentes, o que sobra na primeira $\left(a^{2}\right)$ é igual ao que sobra na segunda $\left(b^{2}+c^{2}\right)$. Então: $a^{2}=b^{2}+c^{2}$.
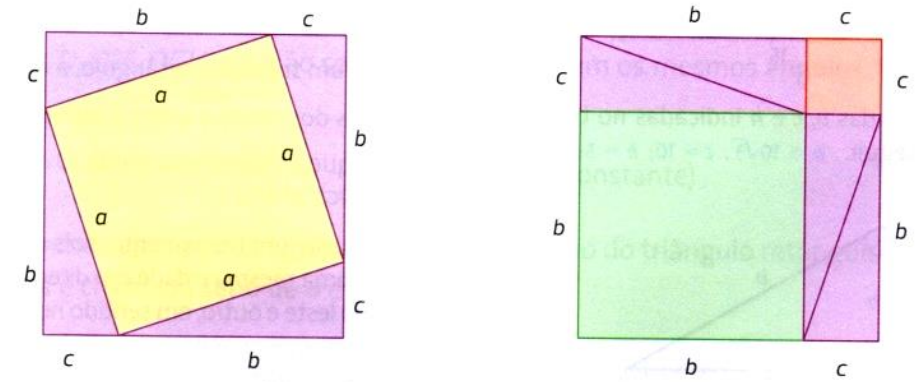

Fonte: Dante (2016, p. 247)

Por fim, o autor encerra o tópico com atividades que apresentam aplicações diretas das relações métricas. 


\section{Apontamentos e Considerações}

Partindo dos resultados da análise do volume 1 que compõem a coleção do livro didático, no que diz respeito à adequação epistêmica, em geral, identifica-se a presença do uso de situações da vida real para introduzir direta ou indiretamente o tema proposto bem como nas tarefas propostas.

Nas tarefas resolvidas, foram contempladas exercícios de natureza da própria matemática bem como contextualizadas. A apresentação da resolução é conferida passo a passo, com clareza e estruturada como base para as tarefas propostas.

Em relação aos conhecimentos prévios, de modo geral, não apresentam atividades de revisão de conceitos, sendo estas apenas sugeridas indiretamente, pelo autor, nas orientações do professor que segundo os pressupostos das adequações didáticas da EOS auxiliam na compreensão dos conceitos. São apresentadas somente atividades de retomada e ampliação de conteúdos aos tópicos estudados neste volume.

As atividades de modelação matemática e de representação visual não foram contempladas neste volume. As atividades de aplicação de propriedade, cálculo, prova e problemas-processos ou heurísticos foram pouco sugeridas.

Para adequação mediacional, é necessário que se incentive o uso de tecnologia (softwares) e recursos digitais como ferramentas para manipulação, compreensão, investigação e exploração das propriedades e relações matemáticas.

Analisando as categorias que compõem a adequação epistêmica, com relação às situaçõesproblema, o autor introduz a unidade de trigonometria com uma imagem e um pequeno texto informativo, os quais buscam despertar o interesse do aluno pelo que será estudado. Na introdução do primeiro capítulo aborda a temática de Geometria sobre semelhança de triângulos que se inicia com um pequeno texto histórico sobre Tales de Mileto e o Teorema de Tales. Apresentando os tópicos de semelhança de triângulos, relações métricas no triângulo retângulo e relações métricas no triângulos retângulo.

Os exemplos resolvidos estão no contexto da própria Matemática ou da semirrealidade, carecendo no contexto de ouras áreas da ciência ou da vida real e localizam-se depois das definições. As tarefas propostas, em geral, são contextualizadas ou são interdisciplinares, como podemos observar no exemplo abaixo. 
Figura 10 - Atividade interdisciplinar

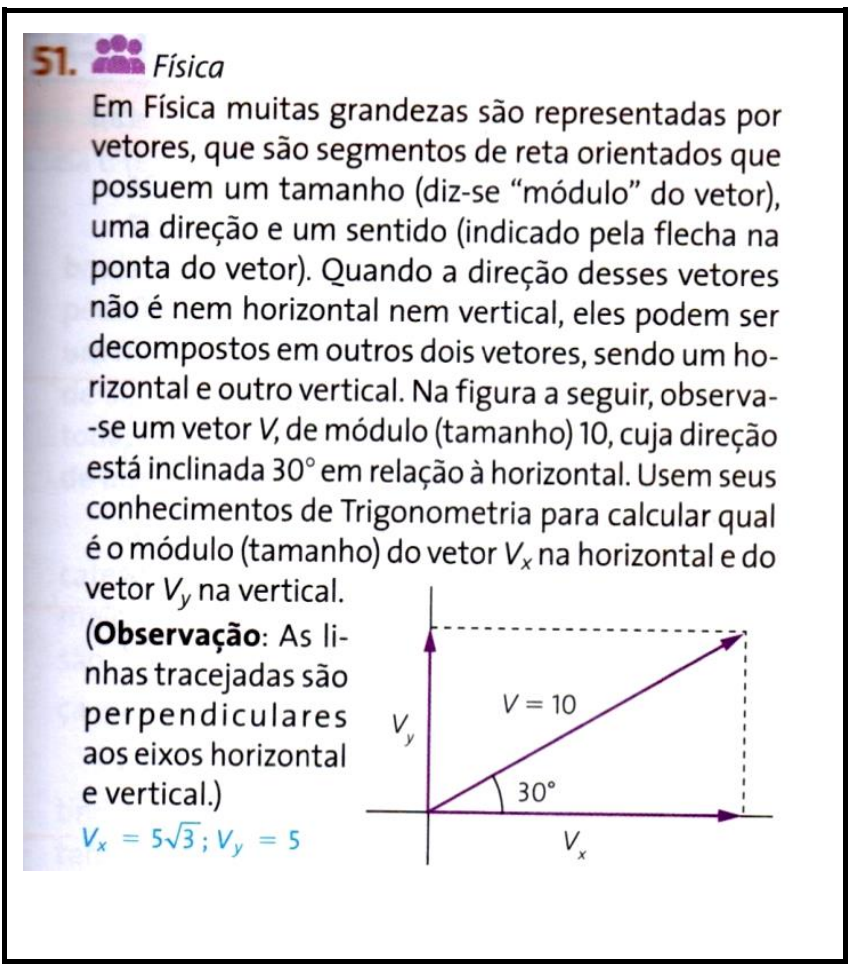

Fonte: Dante (2016, p. 259)

No tocante às atividades de conhecimentos prévios ou revisão de conteúdo, não apresentam atividades específica, porém algumas tarefas são de retomada de conteúdos já estudados na própria unidade. É previsto que os alunos já tenham visto semelhança de triângulos no $9^{\circ}$ ano do ensino fundamental, caso não tenha visto, é fundamental que seja trabalhado neste momento.

Nos conhecimentos emergentes, 0 autor dá maior ênfase nas tarefas que compõem a categoria de cálculo, conforme o grafico abaixo:

Gráfico 1 - Adequação epistêmica: conhecimentos emergentes - Volume 1

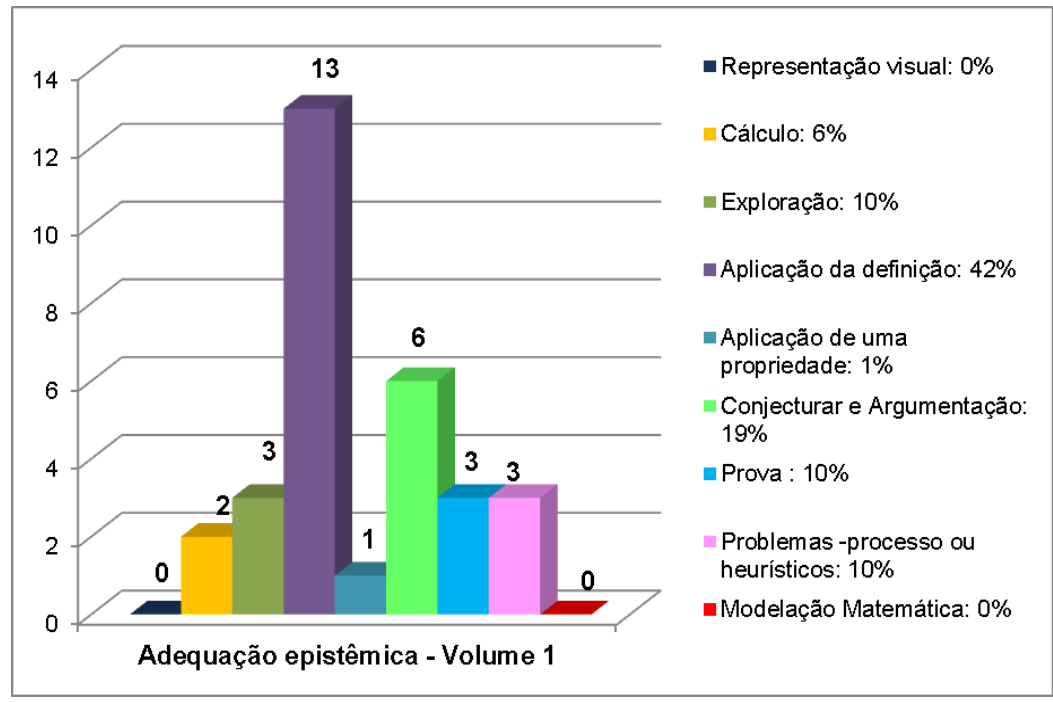

Fonte: Pesquisadores 
Quanto à linguagem, há um equilíbrio no emprego da linguagem usual e da linaguem matemática tornando a comunicação, clara, acessível e apropriada ao aluno da série correspondente. As situações de expressão matemática propostas possibilitam usar as próprias representações para organizar, registrar e comunicar ideias.

Nas categorias de conceitos, proposições, procedimentos e argumentação, os conteúdos são expostos de forma clara e são apropriados para a série correspondente, apresentando situações as quais dão oportunidade para o aluno argumentar, formular hipótese e generalizar. Contudo, poucas são as oportunidades de construção autônoma dos conceitos.

Analisando a adequação mediacional, percebe-se que faz uso de recursos manipuláveis para medir distâncias inacessíveis e o uso da calculadora, para auxiliar nas resoluções das atividades, porém não houve alguma atividade indicando o seu uso com finalidade de investigar propriedades matemáticas, conforme é sugerido no manual do professor. A seguir, segue uma atividade com uso de calculadora:

Figura 12 - Atividade com uso de calculadora

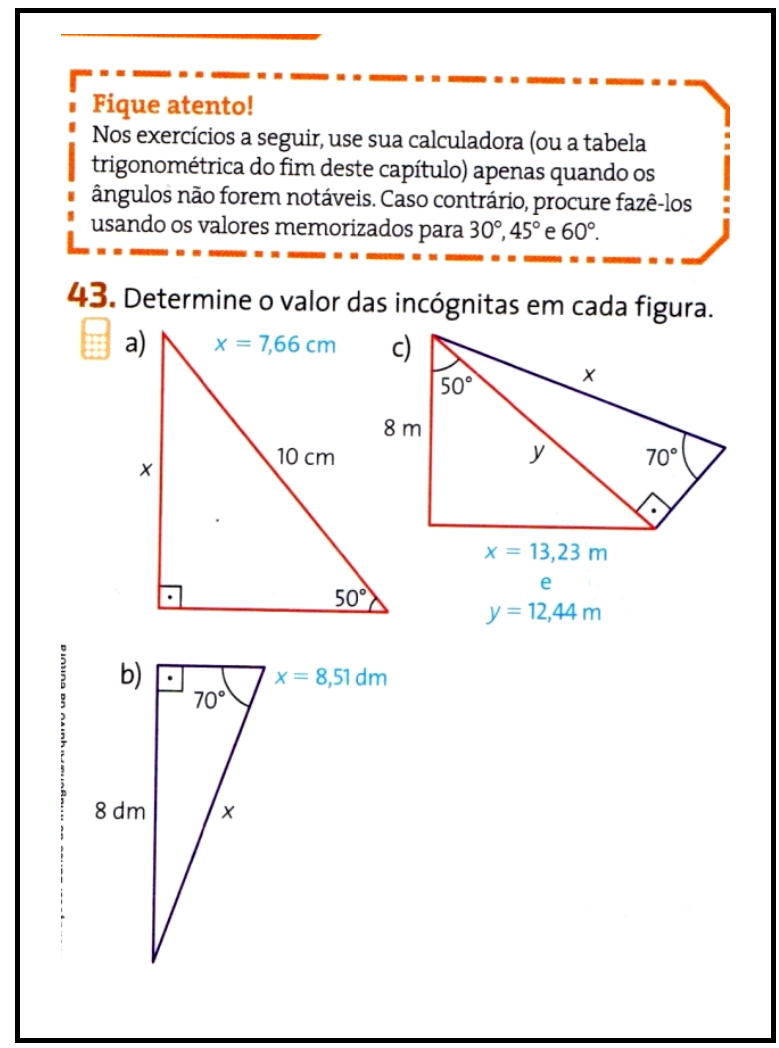

Fonte: Dante (2016, p. 258)

Sabendo que os recursos tecnológicos integram o processo de ensino e aprendizagem e muitos dos problemas podem ser abordados com o apoio de softwares, o uso do GeoGebra seria um bom suporte para representar construção de figuras planas, no caso triângulos no intuito de verificar semelhanças. Além de proporcionar a ampliação e redução de figuras planas, também possibilita a oportunidade dos alunos perceberem regularidades como a proporcionalidade e a soma dos triângulos internos é igual a $180^{\circ}$. 
Para a adequação ecológica, apesar deste volume apresentar maior enfoque na álgebra, a Geometria contempla o currículo. Nota-se uma contribuição na adaptação socioprofissional e cultural e educação em valores por meio de atividades em equipe com a intenção de valorizar a iniciativa e a capacidade de decisão dos alunos possibilitando um ambiente colaborativo e reforçando a ética e a solidariedade.

Quadro 4 - Análise do Volume 1

\begin{tabular}{|c|c|c|c|c|}
\hline \multicolumn{5}{|c|}{ ADEQUAÇÃO EPISTÊMICA } \\
\hline Categorias & \multicolumn{2}{|c|}{ Subcategorias } & \multicolumn{2}{|l|}{ Análise do livro } \\
\hline \multirow{9}{*}{ 1. Situações } & 1.1 Introdução /Motivaçã & & $\begin{array}{l}\text { Introduz por meio de um conte } \\
\text { histórico da própria matemátic } \\
\text { Teorema de Tales para aborda } \\
\text { de semelhança de triângulos. }\end{array}$ & obre \\
\hline & 1.2 Exemplos (tarefas re & olvidas) & $\begin{array}{l}\text { Estão mais presentes as taref } \\
\text { formais da própria matemática } \\
\text { forma discreta, alguns exempl } \\
\text { estão no contexto da semirrea } \\
\text { e das situações da vida real. } \\
\text { Localizam-se depois da definic } \\
\text { formal, a resolução é desenvo } \\
\text { completa, estruturando-se con } \\
\text { modelos de resolução de ativic }\end{array}$ & \\
\hline & & $\begin{array}{l}\text { Conhecimentos } \\
\text { Prévios }\end{array}$ & $\begin{array}{l}\text { Não há atividade específica pa } \\
\text { testar os conhecimentos prévi } \\
\text { Alguns exemplos estão relacio } \\
\text { à retomada de conceitos. }\end{array}$ & \\
\hline & Tomfor 4 & & $\begin{array}{l}\text { 1- Construções de figuras } \\
\text { geométricas: }\end{array}$ & 0 \\
\hline & $\begin{array}{l}\text { autores propõem ao } \\
\text { aluno) }\end{array}$ & Conhecimentos & 2 - Cálculo: & 2 \\
\hline & & & 3 - Exploração: & 3 \\
\hline & & & 4 - Aplicação da definição: & 26 \\
\hline & & & $\begin{array}{l}5 \text { - Aplicação de uma } \\
\text { propriedade: }\end{array}$ & 1 \\
\hline & & & 6 - Conjecturar e argumentar & 6 \\
\hline
\end{tabular}




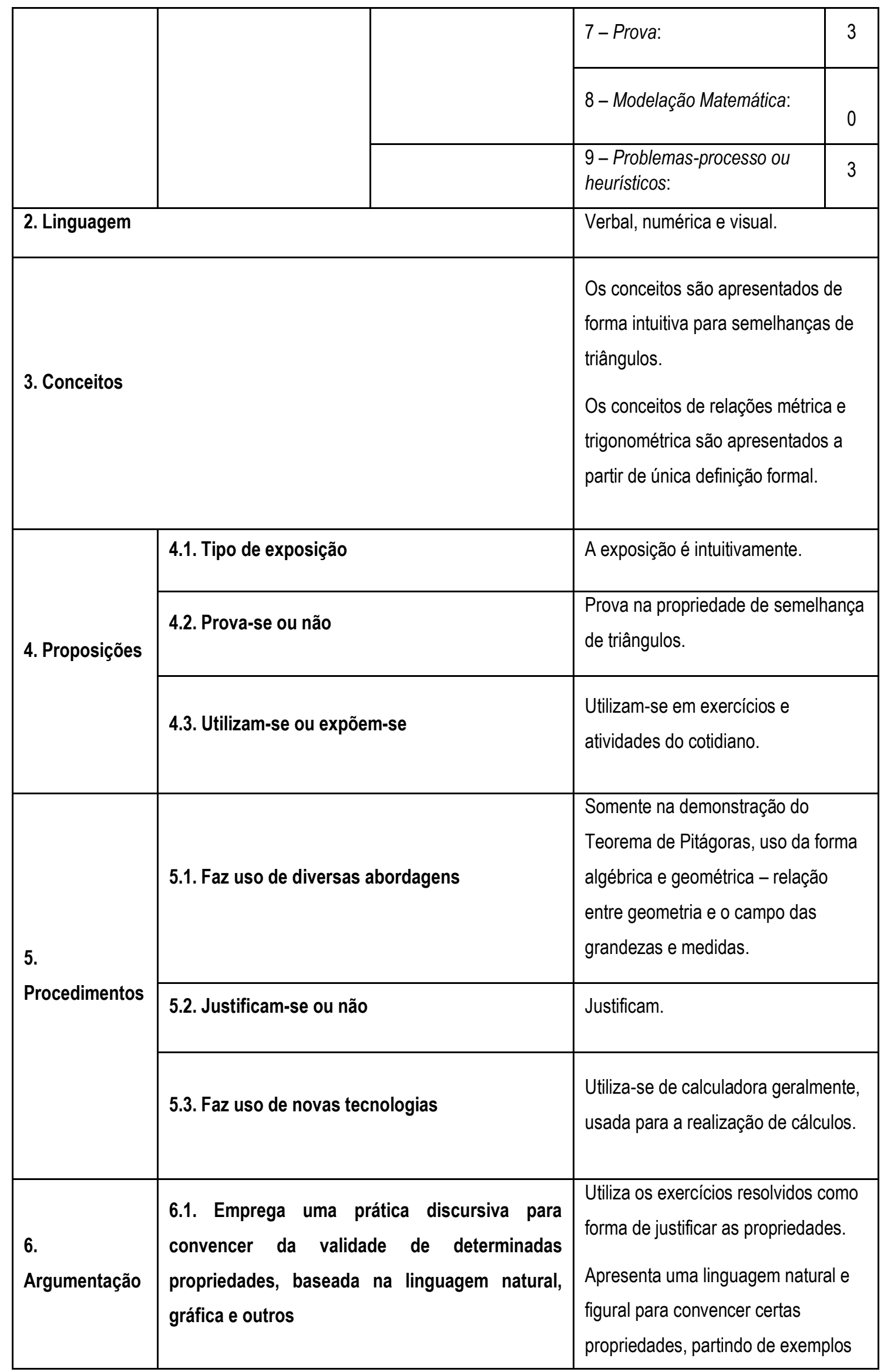




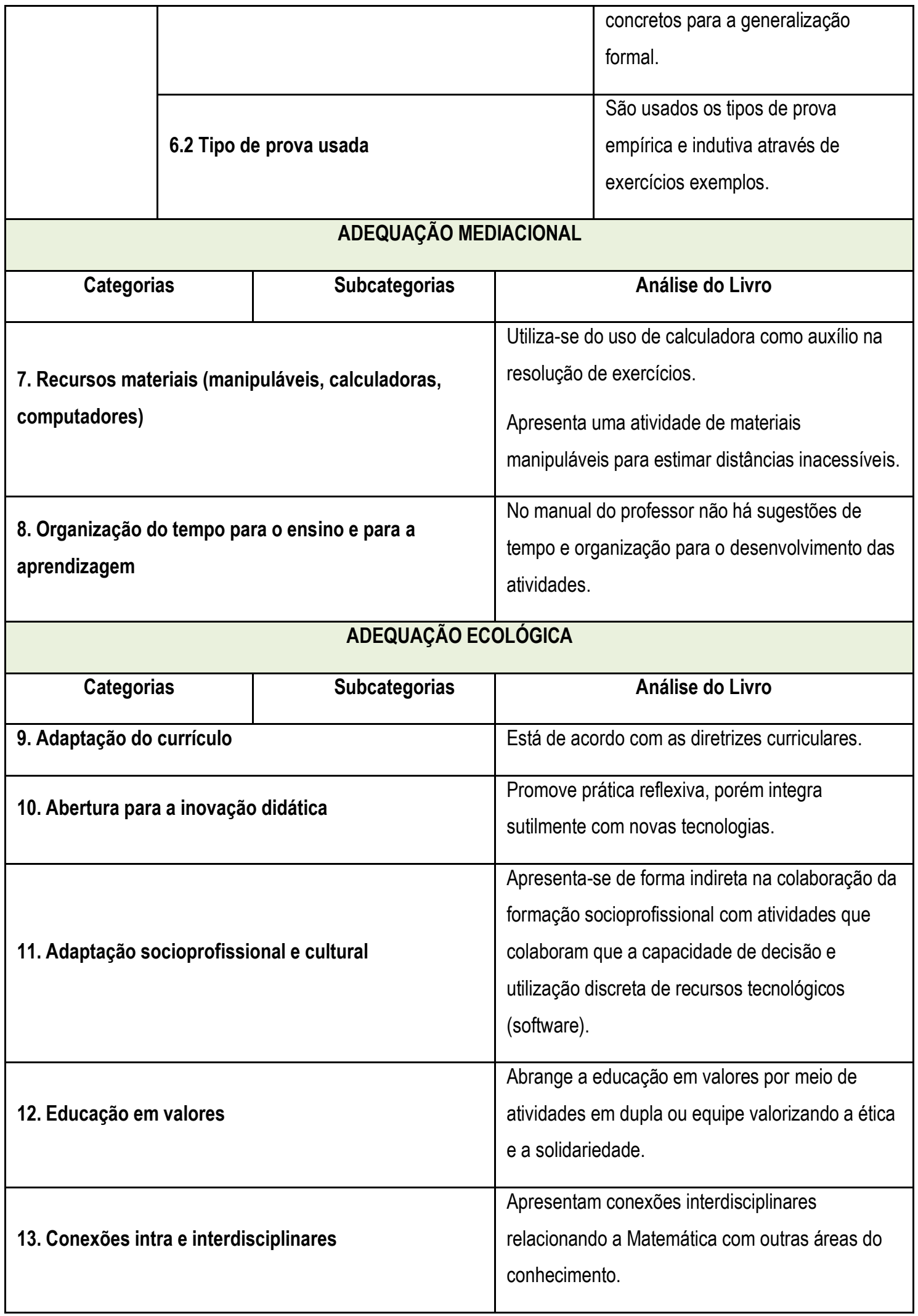

Fonte: Pesquisadores

Nesse sentido, é que o presente estudo buscou avaliar qualitativamente o tema de Geometria em uma coleção de livro didático de matemática adotada nos cursos de ensino técnico 
integrado ao ensino médio a partir do Enfoque Ontossemiótico empregando, especificamente, a ferramenta de adequação didática

Por fim, o tema Geometria, possibilita analisar e representar uma compreensão da realidade de forma ordenada e organizada. Segundo Fainguelernt (1999, p. 15) "A Geometria é considerada como uma ferramenta para compreender, descrever e interagir com o espaço em que vivemos". Portanto possibilita ao aluno ter os ambientes reais como referência para compreender o pensamento geométrico. Assim, as contribuições resultantes de seu estudo se tornam peças fundamentais para explorar a percepção espacial, visualização e conceitos geométricos empegados nos livros didáticos.

Ressaltamos ainda, o uso dos quadros de adequação didática do Enfoque Ontossemiótico como uma ferramenta para análise de livros didáticos, pois, estes compilam diversas categorias que podem auxiliar docentes na exploração destes materiais, um vez que, as adequações epistêmica, mediacional e ecológica são utilizadas para intervir no processo de ensino e aprendizagem.

As categorias e subcategorias das adequações epistêmica, mediacional e ecológica, são elementos que colaboram na compreensão das concepções de um determinado material curricular, permitindo que o professor consiga verificar em quais categorias ou subcategorias necessitam de complementos, ajustes ou aprimoramento de modo a favorecer melhoria na qualidade do ensino e aprendizagem.

Tais categorias que compõem os quadros de análise, carateriza-se como um dispositivo didático, pois o professor consegue selecionar tarefas do material curricular que contemplem os níveis dos conhecimentos emergentes seja mais adequado de acordo com o propósito daquela determinada aula.

Por fim, considera-se a aplicabilidade dos quadros de análise das adequações epistêmicas, mediacional e ecológicas como um possível dispositivo orientador para a análise de materiais curriculares. 


\section{Referências}

BATISTA, Antônio Augusto G. Um objeto variável e instável: textos, impressos e livros didáticos. In: Márcia Abreu (org.) Leitura, história e história da leitura. Campinas: Editora Mercado de Letras, 1999.

CAVALCANTI, Taisa Ferreira Souza; SILVA, Alexsandro da. Os processos e critérios de escolha de livros didáticos de português: o que dizem os professores? In: SOUZA, F. M., and ARANHA, S. D. G., orgs. Interculturalidade, linguagens e formação de professores [online]. Campina Grande: EDUEPB, 2016. Ensino e aprendizagem collection, vol. 2. p. 67-102.

DANTE, Luiz Roberto. Didática da resolução de problemas de matemática. 12ª ed. São Paulo: Ática, 2005.

DANTE, Luiz Roberto. Matemática contexto \& aplicações: ensino médio, $3^{\text {a }}$ ed. São Paulo: Ática, 2016, v.1, p. 235-267, 2, 3.

FAINGUELERNT, Estela Kaufman. Educação matemática: representação e construção em geometria. Porto Alegre: Artes Médicas Sul, 1999.

FONSECA, Carla Isabel Teixeira Tavares Rebimbas da. As Funções Exponencial e Logarítmica nos Manuais Escolares do $1^{\circ}$ ano. 2013. 153f. Dissertação (Mestrado em Didática) - Departamento de Educação, Universidade de Aveiro. Aveiro, Portugal.

GODINO, Juan Díaz. Indicadores de la idoneidade didáctica de processos de enseñanza y aprendizaje de las matemáticas. In: XIII CIAEM - IACME. Anais. Recife, 2011. Disponível em:

<http://www.ugr.es/ jgodino/eos/jdgodino_indicadores_idoneidad.pdf>. Acesso em: 05 set. 2019.

GODINO, Juan Díaz. Origen y aportaciones de La perspectiva ontosemiótica de investogación em Didáctica de la Matemática. In: A. Estepa, A. Contreras, J. Deulofeu, M. C. Penalva, F. J. García y L. Ordóñez (org.), Investigación em Educación Matemática XVI. Jaén: SEIEM, p. 49-68, 2012. Disponível em: <http://www.ugr.es/ jgodino/eos/origen_EOS_Baeza_2012.pdf>. Acesso em: 12 ago. 2019.

GODINO, Juan D.; BATANERO, Carmen; BURGOS, María; GEA, María Magdalena. Uma perspectiva ontosemiótica dos problemas e métodos de pesquisa em educação matemática. Revemop, v. 3, p. e20210, 21 jun. 2021.

GODINO, Juan Díaz; BATANERO, Carmen; FONT, Vicenç; : Um enfoque onto-semiótico do conhecimento e a instrução matemática. Acta Scientiae: Revista de Ensino de Ciências e Matemática, v. 10, n. 2, 2008. Disponível em: <https://www.ugr.es/ jgodino/funciones-semioticas/sintesis_eos_portugues.pdf> Acesso em: 13 ago. 2019.

LAJOLO, Marisa. Livro didático: um (quase) manual de usuário. Em aberto, Brasília, n. 69, v. 16, jan./mar. 1996.

PALANCH, Wagner Barbosa Lima. Mapeamento de Pesquisas sobre Currículos de Matemática na Educação Básica Brasileira (1987 a 2012). 2016. 289f. Tese (Doutorado em Educação Matemática), Pontifícia Universidade Católica de São Paulo, São Paulo.

PIRES, Célia Maria Carolino. Investigações e vivências sobre a utilização de materiais curriculares por professores de matemática. Educação Matemática em Revista, v. 31, n. 48, p. 47-63, mar. 2016.

RIBEIRO, Fernanda Lisboa; PALANCH, Wagner Barbosa de Lima. The Use of the Ontosemiotic Approach to an Analysis of Geometry in Brazilian Curricular Materials. ACTA SCIENTIAE, v. 21, n. 2, p. 18-27, mar/abr. 2019. 